\title{
Biomechanical Model of Hurdle Clearance in 100m Hurdle Races: A Case Study
}

\author{
Milan Coh ${ }^{1}$, Milan Zvan ${ }^{1}$, Nejc Boncina ${ }^{1}$, Stanko Stuhec ${ }^{1}$ \\ 'University of Ljubljana, Faculty of Sport, Ljubljana, Slovenia
}

\begin{abstract}
The purpose of the study was to identify and analyze the biomechanical structure of the hurdle clearance of the sixth hurdle in the 100-m hurdle race of Sally Pearson, the Olympic and world champion. An analysis of the hurdle clearance technique was carried out at the IAAF World Challenge - Zagreb 2011 international competition. 3-D kinematical analysis was utilized along with Ariel Performance Analysis System (APAS) for data processing. Digitization of the 15-segment model of the athlete's body, which was defined with 17 reference points, was performed. The results of the study show the extreme rationality of the hurdle clearance technique, which is demonstrated in the time interval between takeoff and landing $(0.31$ seconds), in the short contact times of the takeoff phase ( 0.10 seconds) before the hurdle and landing following the hurdle clearance $(0.09$ seconds), in the low flight parabola of the central TT $(0.25 \mathrm{~m})$, in the minimal decrease in horizontal velocity $(1.5 \%)$, and in the efficient transition between the hurdle clearance and the sprint between hurdles. The obtained parameters can serve as orientational model values in the 100-m hurdle running technique training process for athletes.
\end{abstract}

Key words: Hurdle Race, Technique, Biomechanics, Kinematics, Case Study

\section{Introduction}

The biomechanical model of hurdle clearance for the $100-\mathrm{m}$ hurdle race is based on the technique of the Australian athlete Sally Pearson, one of the world's greatest runners of $100-\mathrm{m}$ hurdle events. The greatest achievement of her career thus far has been winning the gold medal in the $100-\mathrm{m}$ hurdle race at the London Olympic Games in 2012. She holds many other top achievements such as the gold medal at the Daegu World Championship in 2011, the gold medal at the 2017 World Championships in London, the silver medal at the 2008 Beijing Olympics, and the silver medal at the 2013 World Championship in Moscow. Her personal record for the $100-\mathrm{m}$ hurdle event is 12.28 seconds, which is the sixth fastest time in the history of the event. All these achievements rank Sally Pearson among the most elite athletes of modern athletics.

High hurdle races are among the most technically demanding athletic disciplines. According to previous studies (Schluter, 1981; Mero \& Luhtanen, 1986; La Fortune, 1988;
Bruggemann \& Glad, 1990; McDonald \& Dapena, 1991; Dapena, 1991; McLean, 1994; Iskra, 1998; Kampmiller, Slamka, \& Vanderka, 1999; Čoh, 2001; Blazevich, 2013) the hurdle clearance technique is one of the key elements that determines a competitive result. From a biomechanics standpoint, the 100-m hurdle race combines the cyclic sprint and the acyclic clearance of 10 hurdles with a height of $0.838 \mathrm{~m}$. The athlete must, therefore, have a high level of sprinting skills, exceptional hip joint mobility (flexibility), fast power, and a high level of technical knowledge. During the hurdle clearance, the loss of horizontal velocity must be kept to a minimum. This ability depends on a number of factors, especially those that define the takeoff before the hurdle, the trajectory of the movement of the $\mathrm{CM}$ ( $\mathrm{CM}=$ center of mass) and the landing after the barrier (Kampmiller, Slamka, \& Vanderka, 1999; Amritpal \& Shamsher, 2015). In order to achieve rational hurdle clearance, the takeoff point before the hurdle and the landing point following the barrier are essential. The correct position of

\section{Correspondence:}

\section{Montenegro} Sport
M. Coh

University of Ljubljana, Faculty of Sport, Gortanova ulica 22, 1000 Ljubljana, Slovenia

E-mail: Milan.Coh@fsp.uni-lj.si 
these two points determines the optimal flight trajectory of the $\mathrm{CM}$, which is reflected in the time duration of the airborne phase, which should be as short as possible (Schluter, 1981; Dapena, 1991). In addition to the correct position of the points, the kinematic-dynamic structure of the takeoff and landing also directly influence the velocity of the hurdle clearance (La Fortune, 1988; McLean, 1994).

The aim of the study was to identify and analyze the biomechanical model of the hurdle clearance of the sixth hurdle in an athlete of the highest quality based on 3-D video analysis of kinematic parameters.

\section{Methods}

Biomechanical analysis of the hurdle clearance technique of the sixth hurdle by Sally Pearson (25 years old, body height $1.67 \mathrm{~m}$, body weight $60 \mathrm{~kg}$, P.R. 100 hurdles 12.28) was performed at the Mladost track-and-field stadium for the IAAF World Challenge international competition - Zagreb 2011, Croatia. The weather conditions were optimal; the outside temperature was $23{ }^{\circ} \mathrm{C}$, the wind velocity was - 0.4 m.s.-1. Permission to carry out biomechanical measurements was obtained from the Technical Delegate of the European Athletics Federation and the organizing committee of the competition. The lane in the zone of the sixth hurdle was covered by two high-frequency cameras CASIO-DIGITAL CAMERA EX-F1 (Casio Computer Co., Ltd.,
Tokyo, Japan), which were interconnected and synchronized. The cameras had a frequency of $300 \mathrm{~Hz}$ with a resolution of 720 $\mathrm{x} 576$ pixels. The zone of the sixth hurdle was calibrated with a reference measuring frame of $2 \mathrm{~m} \times 2 \mathrm{~m} \times 2 \mathrm{~m}$, and eight points of the calibration frame were considered for analysis. The APAS (Ariel Performance Analysis System) computer system for 3-D kinematic analysis was used for data processing. Digitization of the 15 - segment model of the athlete's body, which was defined using 17 reference points (Winter, 2005), was performed. Point coordinates were smoothed using a digital filter with a frequency of $14 \mathrm{~Hz}$. Recording was performed at a frequency of $300 \mathrm{~Hz}$, and point digitization was performed at $100 \mathrm{~Hz}$. The center of mass (CM) was calculated based on anthropometric tables from the digitized points (Winter, 2005).

\section{Results}

According to the results of the biomechanical analysis (Table 1, Figure 1), the athlete had an average velocity of $8.58 \mathrm{~m} / \mathrm{s}$ at the clearance of the sixth hurdle. The total stride length was $3.17 \mathrm{~m}$. The takeoff distance was $2.31 \mathrm{~m}$ or $72.9 \%$ of the total step length over the barrier. The landing distance was $0.86 \mathrm{~m}$ from the hurdle, which represented $27.1 \%$ of the total step length over the barrier. The points of takeoff and landing determine an extremely rational flight parabola of the $\mathrm{CM}$ in relation to the hurdle position.

Table 1. Kinematic parameters of the sixth hurdle clearance (Sally Pearson, result of the 100-m hurdle race 12.68) - IAAF World Challenge, Zagreb, 2011.

\begin{tabular}{|c|c|c|}
\hline PARAMETERS & UNIT & $\mathbf{R}$ \\
\hline Rhythmic Units (Hurdle 5- 6) & $\mathrm{m} / \mathrm{s}$ & 8,58 \\
\hline \multicolumn{3}{|l|}{ TAKE - OFF (braking phase) } \\
\hline Horizontal velocity of CM & $\mathrm{m} / \mathrm{s}$ & 8,76 \\
\hline Vertical velocity of CM & $\mathrm{m} / \mathrm{s}$ & $-0,46$ \\
\hline Velocity resultant of CM & $\mathrm{m} / \mathrm{s}$ & 8,77 \\
\hline Height of $\mathrm{CM}$ & $\mathrm{m}$ & 0,96 \\
\hline Take-off distance & $\mathrm{m}$ & 2,31 \\
\hline \multicolumn{3}{|l|}{ TAKE - OFF (propulsion phase) } \\
\hline Horizontal velocity of CM & $\mathrm{m} / \mathrm{s}$ & 8,51 \\
\hline Vertical velocity of CM & $\mathrm{m} / \mathrm{s}$ & 1,45 \\
\hline Velocity resultant of CM & $\mathrm{m} / \mathrm{s}$ & 8,63 \\
\hline Height of CM & $\mathrm{m}$ & 1,03 \\
\hline Push-off angle & $\circ$ & 81,3 \\
\hline Contact time & s & 0,10 \\
\hline \multicolumn{3}{|l|}{ FLIGHT } \\
\hline Flight time & $s$ & 0,31 \\
\hline Height of TT above the hurdle & $\mathrm{m}$ & 0,25 \\
\hline Maximal height CM & $\mathrm{m}$ & 1,16 \\
\hline \multicolumn{3}{|l|}{ LANDING (breaking phase) } \\
\hline Horizontal velocity of CM & $\mathrm{m} / \mathrm{s}$ & 8,53 \\
\hline Vertical velocity of CM & $\mathrm{m} / \mathrm{s}$ & $-0,93$ \\
\hline Velocity resultant of CM & $\mathrm{m} / \mathrm{s}$ & 8,58 \\
\hline Height of CM & $\mathrm{m}$ & 1,08 \\
\hline Landing distance & $\mathrm{m}$ & 0,86 \\
\hline \multicolumn{3}{|l|}{ LANDING (propulsion phase) } \\
\hline Horizontal velocity of CM & $\mathrm{m} / \mathrm{s}$ & 8,37 \\
\hline Vertical velocity of CM & $\mathrm{m} / \mathrm{s}$ & $-1,03$ \\
\hline Velocity resultant of CM & $\mathrm{m} / \mathrm{s}$ & 8,38 \\
\hline Height of $\mathrm{CM}$ & $\mathrm{m}$ & 1,05 \\
\hline Contact time & s & 0,09 \\
\hline
\end{tabular}




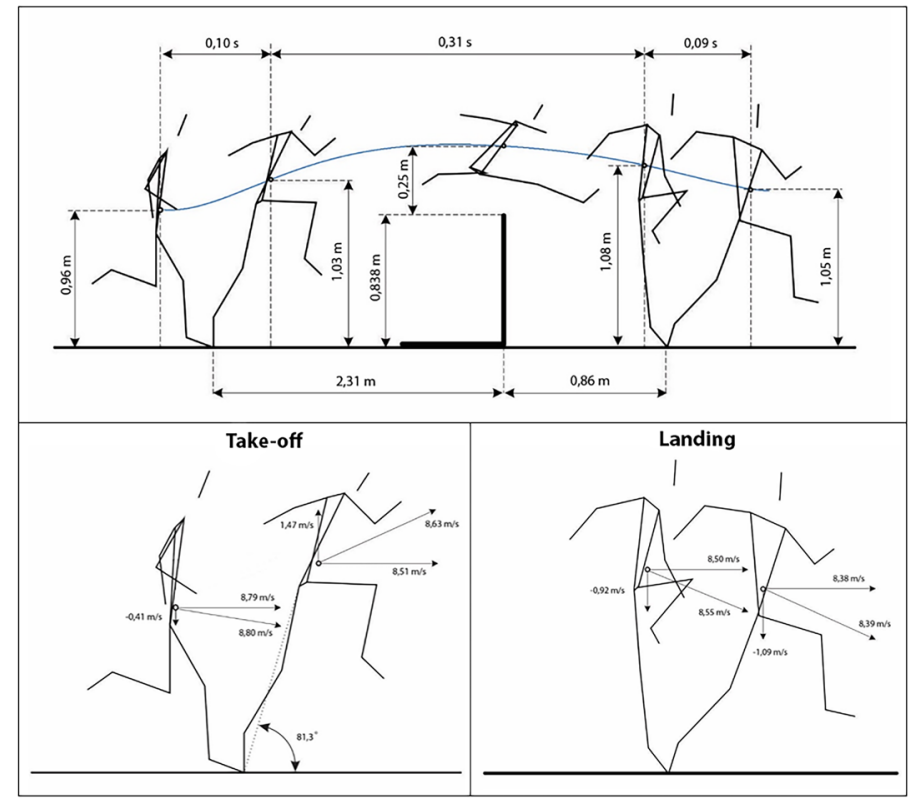

Figure 1. Biomechanical analysis of the sixth hurdle clearance (Sally Pearson, R: $12.68 \mathrm{~s}$ ).

The highest point of the body's center of mass (CM) was $0.25 \mathrm{~m}$ during the hurdle step, while the highest point of the flight parabola was $1.16 \mathrm{~m}$. The difference between the lowest TT point, in the eccentric phase of the takeoff $(0.96 \mathrm{~m})$, before the hurdle and the highest CM point, in the flight phase (1.16 $\mathrm{m}$ ), was $0.20 \mathrm{~m}$. The rationality of the hurdle clearance was also evident in the short flight time, which was $0.31 \mathrm{~s}$.

The push-off angle in the concentric phase of takeoff was 81.3 degrees. The height of the CM at the braking phase was $0.96 \mathrm{~m}$, and $1.03 \mathrm{~m}$ at the end of the propulsion phase of the push-off. The path length of CM in the $\mathrm{Y}$ - vertical axis was
$0.07 \mathrm{~m}$. These parameters provided optimal conditions for the development of velocity of the CM during takeoff.

The horizontal velocity of the TT at the preparatory step of the push-off was $8.79 \mathrm{~m} / \mathrm{s}$, and $8.51 \mathrm{~m} / \mathrm{s}$ at the end of takeoff (Figure 2). The horizontal velocity of the $\mathrm{CM}$ was therefore decreased by $0.28 \mathrm{~m} / \mathrm{s}$ (3.2\%) during takeoff. An important parameter was also the vertical velocity of the CM during takeoff, which was $1.47 \mathrm{~m} / \mathrm{s}$. The horizontal and vertical velocities of the CM determine the propulsion phase resultant velocity at the hurdle, which was measured at $8.63 \mathrm{~m} / \mathrm{s}$ and was directed at an angle of 9.6 degrees.
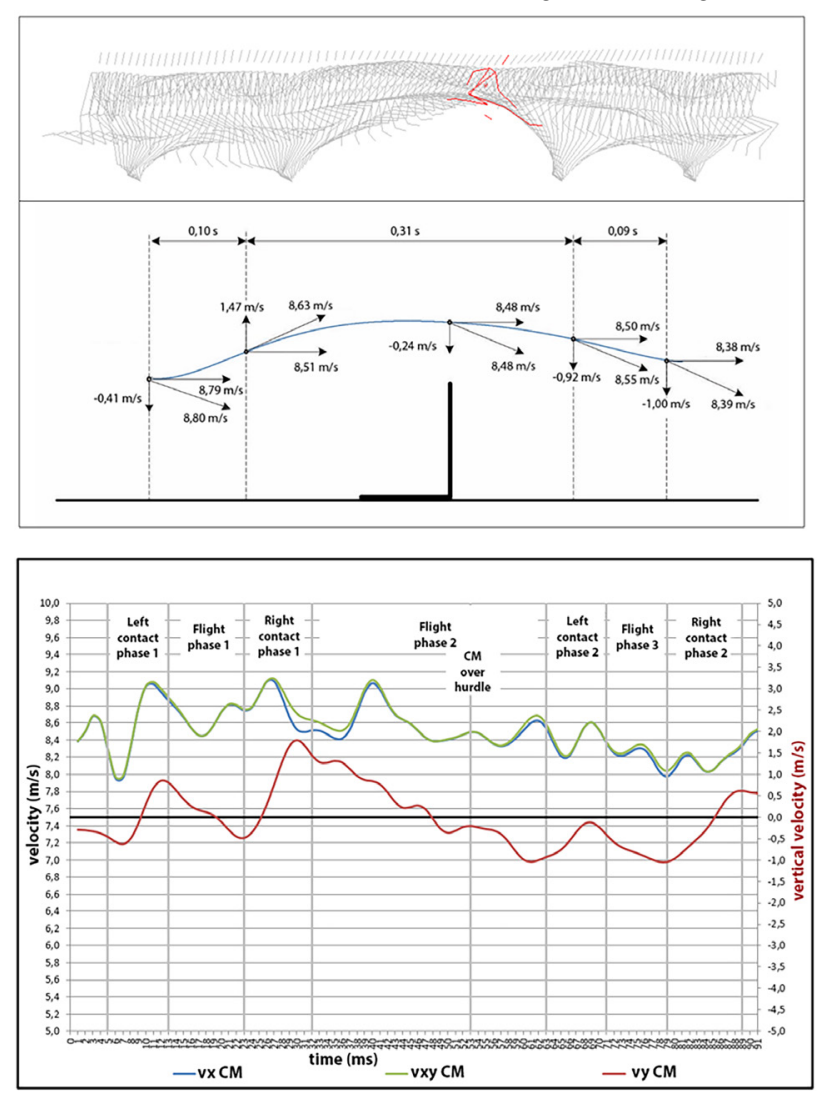

Figure 2. Analysis of the velocity of the central point of the body's center of gravity (TT) during the clearance of the sixth hurdle (Sally Pearson, R: $12.68 \mathrm{~s}$ ). 


\section{Discussion}

The transition from the hurdle clearance to the sprint between hurdles depends on the landing phase. In the case of Sally Pearson, the horizontal velocity of the CM after hurdle clearance was $8.38 \mathrm{~m} / \mathrm{s}$, which means that when the hurdle was cleared, the velocity was decreased by $0.13 \mathrm{~m} / \mathrm{s}(1.5 \%)$. According to previous studies (Mero \& Luhtanen, 1986), this represents a very small decrease in velocity at hurdle clearance and is one of the decisive technical factors that determines this elite athlete.

At the moment of initial contact, following the hurdle clearance, the height of the $\mathrm{CM}$ was $1.08 \mathrm{~m}$. During the landing phase, the height of the CM was decreased by $0.03 \mathrm{~m}$, and at the moment of push-off this height value was $1.05 \mathrm{~m}$. The small decrease in the height of the CM (2.8\%) during the landing phase and the short duration of this phase $(0.09 \mathrm{~s})$ indicates an efficient and rational transition into the sprint between hurdles. To maintain horizontal velocity after the hurdle clearance, the contact time of the landing is very crucial, and must last less than 100 milliseconds (La Fortune, 1988; McLean, 1994).

In addition to the correct landing technique following the hurdle clearance, the ability of the muscular system to resist rapid stretching or stiffness is important. Stiffness, as a neural mechanism of muscle activity, depends primarily on muscle preactivation and reflexes: the myotatic and Golgi tendon reflexes (Gollhofer \& Kyrolainen, 1991). Depending on the biomechanical characteristics of the landing step, it is characterized by short-range elastic stiffness, where an immediate mechanical response of the activated muscle to eccentric contraction at landing takes place. The parameters mentioned above, in particular, the short contact time of the landing step (90 milliseconds) after hurdle clearance and the extremely small decrease in horizontal velocity after clearing the barrier, indicate an efficient and biomechanically rational hurdling technique.

The present study examined the rationality of the hurdle clearance technique of Sally Pearson, the Olympic winner of the 100-m hurdle race, by using modern diagnostic technology for biomechanical analysis. Technique analysis highlighted the small difference between the height of the $\mathrm{CM}$ and the height of the hurdle at the moment of hurdle clearance and the exceptionally small decrease in velocity at the transition from hurdle clearance to the sprint between barriers. The contact phases before and after the hurdle clearance were extremely short, indicating the athlete's high capacity for reactive power. This reactive power makes it possible for the competitor to maintain a high sprint velocity between hurdles, which contributes to her top achievements in running 100-meter hurdle races and has established her as one of the best competitors in this discipline in the history of track-and-field.
Acknowledgements

Pictorial and graphics software is the copyrighted work of Stanko Štuhec.

\section{Conflict of Interest}

The authors declare that there are no conflicts of interest.

Received: 7 June 2019| Accepted: 4 July 2019| Published: 11 October 2019

\section{References}

Amritpal, S., \& Shamsher, S. (2015). Relationship Among the Technique of Hurdle Clearance Over the Different Hurdles in $110 \mathrm{~m}$ Race. International Journal of Science and Research, 4(10), 1591-1594.

Blazevich, A. (2013). Sports biomechanics: the basics: Optimising human performance. London: A\&C Black Publishers Ltd.

Bruggemann, G., \& Glad B. (1990). Time analysis of the sprint events. In Bruggeman, G., \& Glad, B. (Eds.) IAAF Scientific Research Project at the Games of the XXXIV Olympiad Seoul 1998: Final repon (10-45). Florence: Arti Grafiche Danesi.

Čoh, M. (2001). Biomehanika atletike. Ljubljana: Fakulteta za šport.

Dapena, J. (1991). Hurdle clearance technique. Track and Field. Quarterly Review, 116(3), 710-712.

Gollhofer, A., \& Kyröläinen, H. (1991). Neuromuscular Control of the Human Leg Extensor Muscles in Jump Exercises Under Various StretchLoad Conditions. International Journal of Sports Medicine, 12(01), 3440. doi:10.1055/s-2007-1024652

Grimshaw, P. N., Marar, L., Salo, A., Knight, G., \& Vernon, J. (1995). A kinematic analysis of sprint hurdles training strategies (isolation drills). Athletics Coach, 29(4), 24-28.

Iskra, J. (1998). Bieg przez plotki - Teoretyczne podstawy i praktyczne rozwiazania treningowe. Katowice: Akademii Wychowania Fizycznego.

Jarver, J. (1997). The hurdles: Contemporary theory, technique and training. Mountain View, California:Tafnews Press.

Kampmiller, T., Slamka, M., \& Vanderka, M. (1991). Comparative biomechanical analysis of $110 \mathrm{~m}$ hurdles of Igor Kovač and Peter Nedelicky. Kinesiologia Slovenica, 5(1-2), 26-30.

La Fortune, M. (1988). Biomechanical analysis of $110 \mathrm{~m}$ hurdles. Track and Field News, 105, 3355-3365.

Mc Farlane B. (1994). Hurdles: a basic and advanced technical model. Track Technique, 128(1), 4073-4079.

McDonald, C., \& Dapena, J. (1991). Linear kinematics of the men's and woman's hurdles races. Medicine and Science in Sports Exercise, 23(12), 1382-1402.

McLean, B. (1994). The biomechanics of hurdling: Force plate analysis to assess hurdling technique. New Studies in Athletics, 4, 55-58.

Mero, A., \& Luhtanen, P. (1986). Biomechanische Untersuchung des Hurdenlaufs wahrend der Weltmeisterschaften in Helsinki. Leistungssport, 1, 42-43.

Salo, A., \& Grimshaw, P. N. (1998). An Examination of Kinematic Variability of Motion Analysis in Sprint Hurdles. Journal of Applied Biomechanics, 14(2), 211-222. doi:10.1123/jab.14.2.211

Salo, A.I.T., Grimshaw, P.N., \& Marar, L. (1997). 3-D biomechanical analysis of sprint hurdles at different competitive levels. Medicine \& Science in Sports \& Exercise, 29(2), 231-237.

Schluter, W. (1981). Kinematische Merkmale der 110-m Hurdentechnik. Leistungssport, 2, 118-127.

Sidbu, A.S., \& Bahadur, S.S.J. (2015). Relationship among the Technique of Hurdle Clearance Over the Different Hurdles in $110 \mathrm{~m}$ Race. International Journal of Science and Research, 4(10), 1591-1594.

Winter, D. (2005). Biomechanics and Motor Control of Human Movement. Hoboken, New Jersey: John Wiley and Sons INC. 